\title{
The incidence of different cystic fibrosis mutations in the Scottish population: effects on prenatal diagnosis and genetic counselling
}

\author{
A E Shrimpton, I McIntosh, D J H Brock
}

\begin{abstract}
We present an analysis of the frequency of 16 different cystic fibrosis (CF) mutant alleles in the Scottish population. Each allele was detected in DNA amplified by the polymerase chain reaction (PCR) either directly on polyacrylamide gels, on agarose gels after restriction enzyme digestion, or by using allele specific oligonucleotides. Among 506 CF chromosomes, of predominantly Scottish origin, the frequencies of the different mutations were $\triangle$ F508 0.71, G551D 0.05, G542X 0.04, R117H $0.01,1717-1 G \rightarrow A ~ 0.01, A 455 E+\triangle 1507+$ R553X $+\mathbf{R} 560 \mathrm{~T}+\mathrm{W} 1282 \mathrm{X}+621+1 \mathrm{G} \rightarrow \mathrm{T}$ combined 0.03 , unpublished 0.01 , and unknown 0.13 . No examples of D110H, R347P, S549N, S549I, or 2566ins AT mutations were found. The relevance of this type of analysis for both prenatal diagnosis and heterozygote screening is discussed.
\end{abstract}

Cystic fibrosis (CF) is the most common, serious, recessively inherited disorder among Caucasians at 1 in 2500 births. Recent data from the USA suggest a median life expectancy of 27 years. ${ }^{1}$ The gene defective in CF has recently been cloned and shown to encode a 1480 amino acid, $168 \mathrm{kd}$ protein named cystic fibrosis transmembrane conductance regulator (CFTR) ${ }^{2}$ The protein shows homology to a family of proteins with unidirectional transportation properties which require ATP hydrolysis and is thought to be involved in the regulation of chloride transport rather than functioning as a chloride channel per se. ${ }^{23}$ Expression of CFTR cDNA in epithelial cells from CF patients restores the normal regulation of chloride ion transport. ${ }^{45}$

Over 50 putative cystic fibrosis mutations have been identified and a nomenclature devised using the

Human Genetics Unit, University of Edinburgh, Western General Hospital, Edinburgh EH4 2XU.

A E Shrimpton, I McIntosh, D J H Brock

Correspondence to Dr Shrimpton.

Received for publication 22 October 1990

Revised version accepted for publication 6 December 1990. single letter amino acid code. For example the R117H mutation $^{6}$ involves an arginine to histidine change at position 117 , whereas $\triangle F 508$ represents the deletion of an amino acid, phenylalanine, at position 508 . Examination of the available data shows that there appears to be a cluster of mutations in the first nucleotide binding fold. ${ }^{78}$

The first mutation described in CFTR, $\triangle F 508,{ }^{9}$ is present at different frequencies in populations of different ethnic origin. ${ }^{10}$ It is therefore likely that other rarer mutations will also be present at varying frequencies in different populations. A knowledge of this variation is required for accurate genetic counselling and for population based heterozygote screening. We have therefore analysed an extensive cohort of Caucasian patients attending cystic fibrosis clinics in and around Edinburgh (and in many cases their immediate families) and a number of families referred to us for prenatal diagnosis through the Scottish Molecular Genetics Consortium ${ }^{11}$ for the mutations in CFTR described in published reports. ${ }^{6-9} 12-15$ A small number of families from England was also analysed.

Searching for common CFTR mutations allows one to modify the population risk of a subject being a $\mathrm{CF}$ carrier. This is a growing area in genetic counselling when cystic fibrosis is known in the family and we present data on the analysis of the partners of CF carriers.

\section{Methods}

POLYMERASE CHAIN REACTION (PCR) AND ANALYSIS Genomic DNA was extracted from whole blood by standard methods or by use of an Applied Biosystems Model 340A DNA Extractor and amplified using 0.5 to 2 units of AmpliTaq $\left({ }^{\mathrm{TM}}\right.$ ) (Perkin-Elmer/Cetus, Hemel Hempstead) in 50 to $100 \mu \mathrm{l}$ of $50 \mathrm{mmol} / \mathrm{l} \mathrm{KCl}$, $2.5 \mathrm{mmol} / \mathrm{l} \mathrm{MgCl}_{2}, 10 \mathrm{mmol} / \mathrm{l}$ Tris-Cl (pH 8.3 at $25^{\circ} \mathrm{C}$ ) under the conditions shown in table $1 \mathrm{~A}$. Where necessary restriction digests were performed on $10 \mu \mathrm{l}$ of PCR product under the conditions recommended by the supplier and then electrophoresed in $2 \%$ agarose, $0.5 \times$ Tris-borate/EDTA (TBE) gels. The $\triangle F 508$ and $\triangle I 507$ mutations were visualised directly 
Table 1 Conditions used for the detection of defined CF mutations. (A) PCR primers, annealing temperatures, and restriction enzymes. (B) Allele specific oligonucleotides and hybridisation temperatures (other conditions as described ${ }^{16}$ ).

\begin{tabular}{|c|c|c|c|}
\hline A Primer sequence & $\begin{array}{l}\text { Annealing } \\
\text { temp }\left({ }^{\circ} \mathrm{C}\right)\end{array}$ & Mutation & $\begin{array}{l}\text { Detection } \\
\text { method }\end{array}$ \\
\hline $\begin{array}{l}\text { Exon } 4 \\
\text { 5' AGTCACCAAAGCAGTACAGC } \\
\text { 5' GCTATTCTCATCTGCATTCC }\end{array}$ & 50 & $\begin{array}{l}\text { R117H } \\
\text { D110H }\end{array}$ & $\begin{array}{l}\text { ASO } \\
\text { ASO }\end{array}$ \\
\hline $\begin{array}{l}\text { 5' } \text { TCACATATGGTATGACCCTC (a) } \\
\text { 5' TTGTACCAGCTCACTACCTA (a) }\end{array}$ & 50 & $621+1 \mathrm{G} \rightarrow \mathrm{T}$ & RFLP MseI \\
\hline $\begin{array}{l}\text { Exon } 7 \\
\text { 5', CAGAACTGAAACTGACTCGG } \\
\text { 5' TGCTCCAAGAGAGTCATACC }\end{array}$ & 50 & R347P & RFLP MspI \\
\hline $\begin{array}{l}\text { Exon } 9 \\
\text { 5' TAATGGATCATGGGCCATGT (a) } \\
\text { 5' ACAGTGTTGAATGTGGTGCA (a) }\end{array}$ & 58 & A455E & ASO \\
\hline $\begin{array}{l}\text { Exon } 10 \\
\text { 5' GTTTTCCTGGATTATGCCTGGCAC } \\
\text { 5' GTTGGCATGCTTTGATGACGCTTC }\end{array}$ & 58 & $\begin{array}{l}\triangle \mathrm{F} 508 \\
\triangle \mathrm{I} 507\end{array}$ & $10 \%$ PAGE \\
\hline \multicolumn{4}{|l|}{ Exon 11} \\
\hline $\begin{array}{l}\text { 5' TTCAGCAATGTTGTTTTGACCAAC } \\
\text { 5' CACAGATTCTGAGTAACCATAATC }\end{array}$ & 52 & $\begin{array}{l}1717-1 G \rightarrow A \\
\text { G542X } \\
\text { S549N } \\
\text { S549I } \\
\text { G551D }\end{array}$ & $\begin{array}{l}\text { ASO } \\
\text { ASO } \\
\text { RFLP DdeI } \\
\text { RFLP DdeI } \\
\text { RFLP HincII } \\
\quad+M b o I\end{array}$ \\
\hline & & $\begin{array}{l}\text { R553X } \\
\text { R560T }\end{array}$ & $\begin{array}{l}\text { RFLP HincII } \\
\text { ASO }\end{array}$ \\
\hline $\begin{array}{l}\text { Exon } 13 \\
\text { 5', TGTGTCTGTAAACTGATGGCTAACAA (b) } \\
5^{\prime} \text { TCTTCGTTAATTTCTTCACTTATTTC (b) }\end{array}$ & 50 & 2566insAT & $10 \%$ PAGE \\
\hline $\begin{array}{l}\text { Exon } 20 \\
5^{\prime} \text { GGTCAGGATTGAAAGTGTGCA (a) } \\
\text { 5' CTATGAGAAAACTGCACTGGA (a) }\end{array}$ & 55 & W1282X & ASO \\
\hline
\end{tabular}

\begin{tabular}{lllc}
\hline B Mutation & \multicolumn{1}{c}{ Oligonucleotide } & Hybridisation temp $\left({ }^{\circ} \mathrm{C}\right)$ \\
\hline D110H & 5' TCCTATCACCCGGAT & (c) & 48 \\
R117H & 5' GAGGAACACTCTATC & (c) & 48 \\
Normal exon 9 & 5', GTTGTTGGCGGTTGCT & (d) & 52 \\
A455E & 5', GTTGTTGGAGGTTGCT & (d) & 52 \\
1717-1G $\rightarrow$ A & 5', TGGTAATAAGACATCTC & (e) & 47 \\
Normal exon 11 & 5', ACCTTCTCCAAGAACT & 46 \\
G542X & 5' ACCTTCTCAAAGAACT & (e) & 50 \\
R560T & 5' CTTTAGCAACGTGAATAAC & (f) & \\
Normal exon 20 & 5' CAACAGTGGAGGAAAGCCTT & (a) & 56 \\
W1282X & 5' CAACAGTGAAGGAAAGCCTT & (a) & 56 \\
\hline
\end{tabular}

Unless otherwise stated, all oligonucleotides were obtained from OSWEL DNA Service (Edinburgh). Other sources: (a) European Community Cystic Fibrosis Consortium. (b) Dr J Dorin. (c) Dr M Dean. (d) Dr B-S Kerem. (e) Dr M Schwart\%. (f) Mr M Schwart\%.

Table 2 Conditions used for the analysis of CF linked RFLPs by PCR.

\begin{tabular}{|c|c|c|c|c|}
\hline Marker & Primers & $\begin{array}{l}\text { Annealing } \\
\text { temp }\left({ }^{\circ} \mathrm{C}\right)\end{array}$ & Enzyme & Reference \\
\hline$X V-2 c$ & $\begin{array}{l}\text { 5' } \text { GTTGAAGTGAATTGAATG } \\
\text { 5' } \text { TGAGTCTCTGCTGCCAGT* }\end{array}$ & 52 & TaqI & 19 \\
\hline KM19 & $\begin{array}{l}\text { 5' TGCATCATATAAGTTGCC } \\
\text { 5' GGCTACACTGTTAATTTT }\end{array}$ & 40 & PstI & 17 \\
\hline J3.11 & $\begin{array}{l}\text { 5' } \\
\text { 5GCACACTAGGGATGTTC } \\
\text { ' GGCAAATAGAAACAGAGG }\end{array}$ & 50 & $M s p \mathrm{I}$ & 17 \\
\hline MP6d-9 & $\begin{array}{l}\text { 5' AATGCAACAATTCACCCAATTGCTCA } \\
\text { 5' GGTTAGGTCAGAGAACAAAGCAAATT }\end{array}$ & 47 & $M s p \mathrm{I}$ & 20 \\
\hline
\end{tabular}

*Beaudet, personal communication. 
by electrophoresis in $18 \mathrm{~cm} 10 \%$ polyacrylamide (29:1 acrylamide:bis-acrylamide) gels. Gels were run at 30 $\mathrm{mA}$ for 2.5 hours $(0.5 \times \mathrm{TBE})$ or 4 hours $(1 \times \mathrm{TBE})$, and stained in $2 \mu \mathrm{g} / \mathrm{ml}$ ethidium bromide.

Hybridisations with the allele specific oligonucleotides shown were performed as previously described ${ }^{16}$ except that Hybond $\mathrm{N}^{+}$membranes (Amersham) were used. The oligonucleotides and hybridisation temperatures used are shown in table $1 \mathrm{~B}$. Whenever possible we analysed DNA from both parents as well as the index case to show that the mutations under study were on separate chromosomes. This has the additional benefit of supporting paternity. Cystic fibrosis linked polymorphisms were also analysed by PCR amplification (table 2). On all samples the XV-2c (TaqI) and KM19 (PstI) genotypes were analysed in order to determine where possible the XV-2c/KM19 haplotypes of the CF chromosomes. We also analysed J3.11 (MspI) and MP6d-9 (MspI) when required to identify cystic fibrosis chromosomes.

\section{Results and discussion}

\section{MUTATION ANALYSIS}

In a previous report we showed that the exon 10 $\triangle$ F508 mutation accounts for $73 \%$ of $\mathrm{CF}$ chromosomes in complete families in the Scottish population. ${ }^{17}$ Thus, in 53\% of families the index case is expected to have inherited this allele from both parents. In the present study we have looked at a larger sample population, of predominantly Scottish origin, and the $\triangle F 508$ frequency is $71 \%$ ( $51 \%$ of index cases having two copies of $\triangle F 508$ ). There was no significant difference between the Scottish and English populations analysed (306/430 Scottish $=71 \cdot 2 \% ; 55 / 76$ English $=71 \cdot 3 \%$ ). Owing to the smaller number of chromosomes in the English sample it is not possible to compare the relative frequencies of the other, rarer mutations described below. In the following discussion, figures are a percentage of all 506 chromosomes analysed (table 3 ).

Using polyacrylamide gel electrophoresis (PAGE) it is possible to discriminate between $\triangle F 508$ and the neighbouring deletion $\triangle \mathrm{I} 507 .{ }^{8} 12$ The heteroduplexes formed between the $95 \mathrm{bp}$ and $98 \mathrm{bp}$ products in the latter stages of PCR migrate through polyacrylamide gels in a conformation dependent manner. The sequence difference between the two deleted products (deletion of ATC/GAT or CTT/AGG) results in different heteroduplex conformations and hence different rates of migration in the gel (figure). $\triangle \mathrm{I} 507$ is a rare mutation which we have observed on three apparently unrelated CF chromosomes.

Of the nine individual point mutations identified in exon 11 of CFTR, ${ }^{712}$ we have searched for six. Of these, two are present at significant levels in the samples analysed (table 3). G551D is detected by digestion with restriction enzymes $H$ incII and $M$ MboI. The $\mathbf{G} \rightarrow \mathbf{A}$ transition at nucleotide 1704 removes a HincII site and creates an MboI site. G542X is detected by the use of an allele specific oligonucleotide (ASO). Three separate mutations affect the serine residue at codon 549. Two of these (S549N and S549I) destroy a DdeI site. We have not observed any chromosomes carrying these mutations. R553X destroys the same HincII site as G551D but does not create another restriction site. The clustering of missense mutations in a putative ATP binding fold indicates the functional importance of this region. ${ }^{3} 78$

Using a combination of chemical modification and direct sequencing (C T Jones et al, in preparation), we identified two putative splice mutations, namely $1717-1 G \rightarrow A$ and $R 560 T$, which had been described previously. ${ }^{8} 1215$ We subsequently analysed these

Table 3 Mutations identified on CF chromosomes from index cases in a predominantly Scottish population.

\begin{tabular}{|c|c|c|c|c|c|}
\hline Mutation & Exon & Haplotype & No & $\%$ & Reference \\
\hline $\begin{array}{l}\text { D110H } \\
\text { R117H } \\
621+1 \mathrm{G} \rightarrow \mathrm{T} \\
\text { R347P } \\
\text { A455E } \\
\triangle 1507 \\
\triangle \mathrm{F} 508 \\
1717-1 \mathrm{G} \rightarrow \mathrm{A} \\
\text { G542X } \\
\text { S549N } \\
\text { S549I } \\
\text { G551D } \\
\text { R553X } \\
\text { R560T } \\
\text { 2566insAT } \\
\text { W1282X } \\
\text { Unpublished } \\
\text { Unknown } \\
\text { Total }\end{array}$ & $\begin{array}{l}4 \\
4 \\
* \\
7 \\
9 \\
10 \\
10 \\
+ \\
11 \\
11 \\
11 \\
11 \\
11 \\
11 \\
13 \\
20\end{array}$ & $\begin{array}{l}\bar{C} \\
\text { B } \\
\bar{B} \\
\text { D } \\
\text { B } \\
\text { B } \\
\text { B } \\
- \\
\text { B } \\
\text { A } \\
\text { D } \\
\text { B }\end{array}$ & $\begin{array}{r}0 \\
7 \\
3 \\
0 \\
1 \\
3 \\
361 \\
5 \\
20 \\
0 \\
0 \\
28 \\
1 \\
3 \\
0 \\
2 \\
7 \\
65 \\
506\end{array}$ & $\begin{array}{l}0 \\
1.4 \\
0.6 \\
0 \\
0.2 \\
0.6 \\
71.3 \\
1.0 \\
4.0 \\
0 \\
0 \\
5.5 \\
0.2 \\
0.6 \\
0 \\
0.4 \\
1.4 \\
12.8\end{array}$ & $\begin{array}{l}6 \\
6 \\
12 \\
6 \\
8,12 \\
8,12 \\
8,9 \\
8,12,15 \\
8,12 \\
7 \\
8,12 \\
7 \\
7 \\
8,12 \\
13 \\
8,14\end{array}$ \\
\hline
\end{tabular}

=intron 4. $t=$ intron 10 . $-=$ not determined.

Haplotypes shown are defined by alleles at the XV-2c and KM19 loci, as follows: A 2.1 kb, 7.8 kb; B 2.1 kb, 6.6 kb; C 1.4 kb, 7.8 kb; D $1.4 \mathrm{~kb}, 6.6 \mathrm{~kb}$, and represent the background on which each mutation was most often observed. 


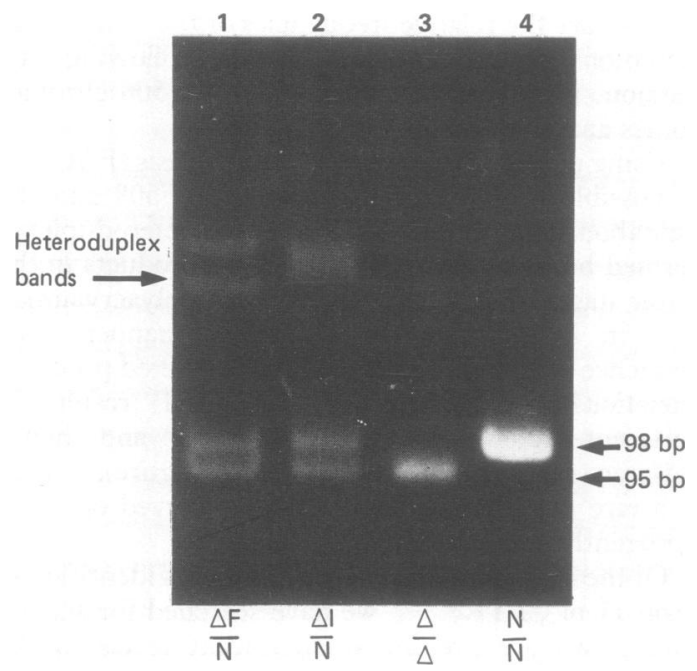

Ethidium bromide stained $10 \%$ polyacrylamide gel showing the direct detection of $\triangle F 508$ and $\triangle I 507$. The samples are from a $\triangle F 508$ heterozygote (lane 1), a $\triangle 1507$ heterozygote (lane 2), a $\triangle F 508$ homozygote (lane 3), and a non-deletion homozygote (lane 4).

using ASO hybridisation and found each represents approximately $1 \%$ of CF chromosomes in the study population.

A number of mutations have been described in the first transmembrane region of CFTR, which appear to be associated with a milder phenotype ${ }^{6}$ Using an allele specific oligonucleotide (gift of $M$ Dean) we have shown one of these, $\mathrm{R} 117 \mathrm{H}$, to be present on approximately $1 \%$ of CF chromosomes in this study. We did not observe either D110H or R347P detectable by allele specific oligonucleotides and $M s p I$ digestion, respectively. Three examples of the $621+1 \mathrm{G} \rightarrow \mathrm{T}$ intron 4 splicing mutation were also detected. ${ }^{12}$ Other mutations identified in the populations studied are shown in table 3. The XV-2c/KM19 haplotype most commonly associated with each mutation identified is also shown. It is clear that the linkage disequilibrium observed between the ' $\mathrm{B}$ ' haplotype $(\mathrm{XV}-2 \mathrm{c} / 2 \cdot 1 \mathrm{~kb}$; $\mathrm{KM} 19 / 6.6 \mathrm{~kb}$ ) and the $\mathrm{CF}$ locus is not the result of linkage to a single mutant allele. A possible explanation of the recurrence of CF mutations on the same haplotype involves a combination of hitchhiking and epistasis. $^{18}$

Four of the mutations we identified are only known to us through the Cystic Fibrosis Genetic Analysis Consortium and cannot be described in detail in this communication. A detailed comparison of genotype and phenotype in the patients studied here will be published separately.

In cases where one or both CFTR mutations await identification, all families analysed can be made fully informative using polymorphic markers linked to the CF locus.
Table 4 Prenatal diagnoses between September 1989 and October 1990.

$\triangle \mathrm{F}^{508 / \triangle F 508}$
$\triangle \mathrm{F508/G551D}$
$\triangle \mathrm{F508/R117H}$
$\triangle \mathrm{F} 508 /$ other $^{*}$
Total

${ }^{*}$ In these cases the other $\mathrm{CF}$ allele was tracked using linked markers.

\section{PRENATAL DIAGNOSIS}

We have performed 21 prenatal diagnoses (table 4), using direct analysis of CFTR mutations, at first using $\triangle F 508$ and then G551D and R117H (as they were identified). All families have been screened for $\triangle F 508, G 551 D, G 542 X$, and R117H, while most have been screened for each of the CF mutations described in this report.

Chromosomes with unidentified CF mutations were followed with CF linked markers shown to be segregating with the mutation. As more CF mutations have been described the proportion of prenatal diagnoses using both mutations rather than $\mathrm{CF}$ linked polymorphisms has increased over the first year. At present over $85 \%$ of families are fully informative for both $\mathrm{CF}$ mutations segregating. (In $137 \mathrm{CF}$ families the index case and both parents were available for analysis. In this subset of the population we have been able to identify $92.5 \%$ of CF mutations, hence the figure of $85 \%$.)

\section{GENETIC COUNSELLING}

The identification of over $85 \%$ of the cystic fibrosis mutations on all CF chromosomes analysed (table 3) has resulted in an increase in workload for the counselling services. In the first instance, the relatives of CF patients and known carriers request carrier status determination. The partners of known carriers subsequently request analysis to determine whether they also carry a CF mutation.

From the data in table 3 , it appears that $\triangle F 508$, G551D, G542X, and perhaps R117H are sufficiently common to justify analysis in the partners of $\mathrm{CF}$ heterozygotes identified in family studies. Exclusion of these four mutations would reduce a subject's risk from 1:25 to 1:136, and hence the apparent risk to the pregnancy from 1:100 to $1: 543$. Analysis for all mutations detected in this population to date reduces these figures to $1: 189$ and $1: 754$, respectively. We have analysed 53 partners of known CF heterozygotes and identified four subjects heterozygous for $\triangle F 508$ and one heterozygous for $\mathrm{R} 117 \mathrm{H}$. This latter observation is particularly interesting since the data in table 3 would predict an overall frequency of 1:1785 for this allele in the population.

Although the population in this study was of largely Scottish origin, the findings are expected to be 
generally applicable to other United Kingdom populations. It will be interesting to compare similar data from other parts of northern Europe.

\section{RECOMBINATION/CARRIER STATUS}

It has become more straightforward and informative to follow CF chromosomes from nuclear families into second degree relatives using the CF mutations rather than by CF linked markers, as there is no increased error owing to recombination. An increased proportion of our families are now being analysed in this way.

To eliminate the possibility of recombination, subjects who had previously been tested for their carrier status with linked markers were analysed once more for the mutation(s) identified in each family. In only one of 78 families was a recombinant between CFTR and linked marker (pJ3.11) identified, but with profound effect to the carrier status assignments within the family. Four subjects were now found to be carriers, having been given a low risk of being carriers by linked marker analysis. One of the subjects whose status was changed was found to have a partner who carried $\triangle \mathrm{F} 508$.

Unaffected sibs of CF index cases with both mutations identified can be screened for their carrier status, and our finding of 39 out of $61 \mathrm{CF}$ carriers was close to the expected two thirds. However there was a just significant ( 50 of $81: 0.05>p>0.02$ ) excess of CF carriers among sibs of known carriers of identified mutations.

\section{NON-PATERNITY}

Out of 100 families in which both cystic fibrosis mutations had been identified, one case of previously undiscovered non-paternity was identified by finding that the 'father' did not carry the appropriate CF mutation found in the index case. This had not been detected earlier despite the family having been studied with nine CF linked polymorphisms. Nonpaternity was confirmed by DNA fingerprint analysis by our colleagues in Aberdeen.

We would like to thank our colleagues in the Scottish Molecular Genetics Consortium for the provision of extracted DNA samples from subjects within their regions and in particular Drs Marion Keston (Edinburgh), Rosemarie Davidson (Glasgow), and John Dean (Aberdeen). We are indebted to the following for oligonucleotides and control DNA samples: Professor J J Cassiman (Leuven), Drs M Dean
(Frederick), J Dorin (Edinburgh), B-S Kerem (Toronto), M Schwartz (Copenhagen), and $\mathbf{M r}$ M Schwarz (Manchester). Work in this laboratory is funded by the Cystic Fibrosis Research Trust, the Scottish Home and Health Department, and the Ludovici Bequest to the University of Edinburgh.

1 Boat TF, Welsh MJ, Beaudet AL. Cystic fibrosis. In: Scriver CR, Beaudet AL, Sly WS, Valle D, eds. The metabolic basis of inherited disease. 6th ed. New York: McGraw-Hill, 1989: 2649-80.

2 Riordan JR, Rommens JM, Kerem BS, et al. Identification of the cystic fibrosis gene: cloning and characterization of complementary DNA. Science 1989;245:1066-73.

3 Hyde SC, Emsley P, Hartshorn MJ, et al. Structural model of ATP-binding associated with cystic fibrosis, multidrug resistance and bacterial transport. Nature 1990;346:362-5.

4 Drum ML, Pope HA, Cliff WH, et al. Correction of the cystic fibrosis defect in vitro by retrovirus mediated gene transfer. Cell 1990;62:1227-33.

5 Rich DP, Anderson MP, Gregory RJ, et al. Expression of cystic fibrosis transmembrane conductance regulator corrects defective chloride channel regulation in cystic fibrosis epithelial cells. Nature 1990;347:358-63.

6 Dean M, Amos J, Hsu JMC, et al. Multiple mutations in highly conserved residues are found in mildly affected cystic fibrosis patients. Cell 1990;61:863-70.

7 Cutting GR, Kasch LM, Rosenstein BJ, et al. A cluster of cystic fibrosis mutations in the first nucleotide-binding fold of the cystic fibrosis conductance regulator protein. Nature 1990;346: 366-9.

8 Kerem BS, Zielenski J, Markiewicz D, et al. Identification of mutations in regions corresponding to the 2 putative nucleotide (ATP)-binding folds in the cystic fibrosis gene. Proc Natl Acad Sci USA 1990;87:8447-51.

9 Kerem BS, Rommens JM, Buchanan JA, et al. Identification of the cystic fibrosis gene: genetic analysis. Science 1989;245: $1074-80$.

10 Cystic Fibrosis Genetic Analysis Consortium. Worldwide survey of the $\triangle F 508$ mutation. Report from the cystic fibrosis genetic analysis consortium. Am $\mathcal{F}$ Hum Genet 1990;47:354-9.

11 Brock DJH. A consortium approach to molecular genetic services. F Med Genet 1990;27:8-13.

12 Kerem B, Bozon D, Zielenski J, et al. Identification of mutations in the cystic fibrosis gene. Am $\mathcal{f}$ Hum Genet 1990;47:223A.

13 White MB, Amos J, Hsu JMC, et al. A frameshift mutation in the cystic fibrosis gene. Nature 1990;344:665-7.

14 Vidaud M, Fanen P, Martin J, Ghanem N, Nicolas S, Goossens $M$. Three point mutations in the CFTR gene in French cystic fibrosis patients: identification by denaturing gradient gel electrophoresis. Hum Genet 1990;85:446-9.

15 Guillermit H, Fanen P, Ferec C. A 3' splice site consensus sequence mutation in the cystic fibrosis gene. Hum Genet 1990;85:450-3.

16 Brind AM, McIntosh I, Brock DJH, James OFW, Bassendine MF. Polymerase chain reaction for detection of the alpha-1antitrypsin $\mathrm{Z}$ allele in chronic liver disease. $\mathcal{F}$ Hepatol 1990;10: $240-3$.

17 McIntosh I, Curtis A, Lorenzo ML, et al. The haplotype distribution of the $\triangle F 508$ mutation in cystic fibrosis families in Scotland. Hum Genet 1990;85:419-20.

18 Wagner DK, Cavalli-Sforza LL. Ethnic variation in genetic disease: possible roles of hitchhiking and epistasis. Am $\mathfrak{\mathcal { F }} \mathrm{Hum}$ Genet 1975;27:348-64.

19 Rosenbloom CR, Kerem BS, Rommens JM, et al. DNA amplification for detection of the XV-2c polymorphism linked to cystic fibrosis. Nucleic Acids Res 1989;17:7117.

20 Huth A, Estivill X, Grade K, et al. Polymerase chain reaction for the detection of the pMP6-9/MspI RFLP, a marker closely linked to the cystic fibrosis mutation. Nucleic Acids Res 1989;17:7118. 